Technical Report

\title{
Double Needle Technique: An Alternative Method for Performing Difficult Sacroiliac Joint Injections
}

Sanjeeva Gupta, MD

From: Bradford Teaching Hospitals NHS Foundation Trust, Bradford, United Kingdom

Dr. Gupta is a Consultant in Pain Medicine and Anaesthesia, Bradford Teaching Hospital NHS Foundation Trust, Bradford Royal Infirmary, Bradford United Kingdom

Address corespondence: Sanjeeva Gupta, MD Consultant in Pain Medicine and Anaesthesia Bradford Teaching Hospital NHS Foundation Trust Bradford Royal infirmary Bradford

United Kingdom $\mathrm{BD} 9$ 6RJ

Email: SGupta6502@aol.com

Disclaimer: There was no external funding in the preparation of this manuscript. Conflict of interest: None.

Manuscript received: 02/04/2011 Revised manuscript received: 02/28/2011 Accepted for publication: 04/07/2011

Free full manuscript: www.painphysicianjournal.com
The sacroiliac joint (SIJ) is a common source of low back pain. The most appropriate method of confirming SIJ pain is to inject local anesthesia into the joint to find out if the pain decreases. Unfortunately, although the SIJ is a large joint, it can be difficult to enter due to the complex nature of the joint and variations in anatomy. In my experience a double needle technique for sacroiliac joint injection can increase the chances of accurate injection into the SIJ in difficult cases. After obtaining appropriate fluoroscopic images, the tip of the needle is advanced into the SIJ. Once the tip of the needle is correctly placed, its position is checked under continuous fluoroscopy while moving the $\mathrm{C}$-arm in the right and left oblique directions (dynamic fluoroscopy). On dynamic fluoroscopy the tip of the needle should remain within the joint line and not appear to be on the bone. If the tip of the needle appears to be on the bone a new joint line will need to be identified (the most translucent area through the joint) by dynamic fluoroscopy and another needle advanced into the newly identified joint line. Dynamic fluoroscopy is repeated again to confirm that the tip of the second needle remains within the joint line. Once both needles are in place contrast dye is injected through the needle that is most likely to be in the SIJ. If the contrast dye spread is not satisfactory then it is injected through the other needle. I have used this technique in 10 patients and found it very helpful in accurately performing SIJ injection which can at times be challenging.

Key words: double needle techique, sacroiliac joint, low back pain, contrast dye, fluoroscopy

Pain Physician 2011; 14:281-284 $\bigsqcup$ he sacroiliac joint (SIJ) is a common source of low back pain. The nerve supply and technique of performing an SIJ injection has been described (1-8). SIJ injections are commonly performed interventional pain management techniques $(9,10)$. SIJ pain is generally unilateral, more common in multiparous women, and in patients likely to have maximum pain below the L5 vertebral body level (4). The most appropriate method of confirming SIJ pain is to inject local anesthesia into the joint to find out if the pain decreases at rest and during activities of daily living (4). Unfortunately, although the SIJ is large, it can be difficult to enter due to its complex nature and variations in individual anatomy.

In clinical practice I have observed that although the tip of the needle may appear to be in the SIJ on fluoroscopy, the contrast dye spread may not indicate so. However, once the contrast dye is injected, it becomes difficult to place another needle as the fluoroscopic landmarks are obscured by the injected contrast dye. In my clinical practice I have done over 60 SIJ injections in the last 5 months and felt the need to use the 
double needle technique which I describe below in 10 patients; I have found this technique very helpful in successfully injecting the SIJ in difficult cases. To my knowledge this technique has not been described before.

\section{Double Needle Technique for Sacroiliac JOINT INJECTION}

After obtaining appropriate fluoroscopic images, the tip of a 3.5-inch long, 22-gauge curved tip spinal needle is advanced into the SIJ (Fig. 1). Once the tip of the needle is correctly placed, its position is checked under continuous fluoroscopy while moving the C-arm in the right and left oblique directions (dynamic fluoroscopy). On dynamic fluoroscopy the tip of the needle should remain within the joint line and not appear to be on the bone. If the tip of the needle appears to be on the bone (Fig. 2), a new joint line will need to be identified (the most translucent area through the joint) by dynamic fluoroscopy and another needle advanced into the newly identified joint line (Fig. 3). Dynamic fluoroscopy is repeated again to confirm that the tip of the second needle remains in the joint line. Once both needles are in place, contrast dye is injected through the needle that is most likely to be in the joint (Figs. 4 and 5). If the contrast dye spread is not satisfactory, then contrast dye is injected through the other needle. I have found this technique very helpful in accurately performing an SIJ injection, which can at times be challenging.

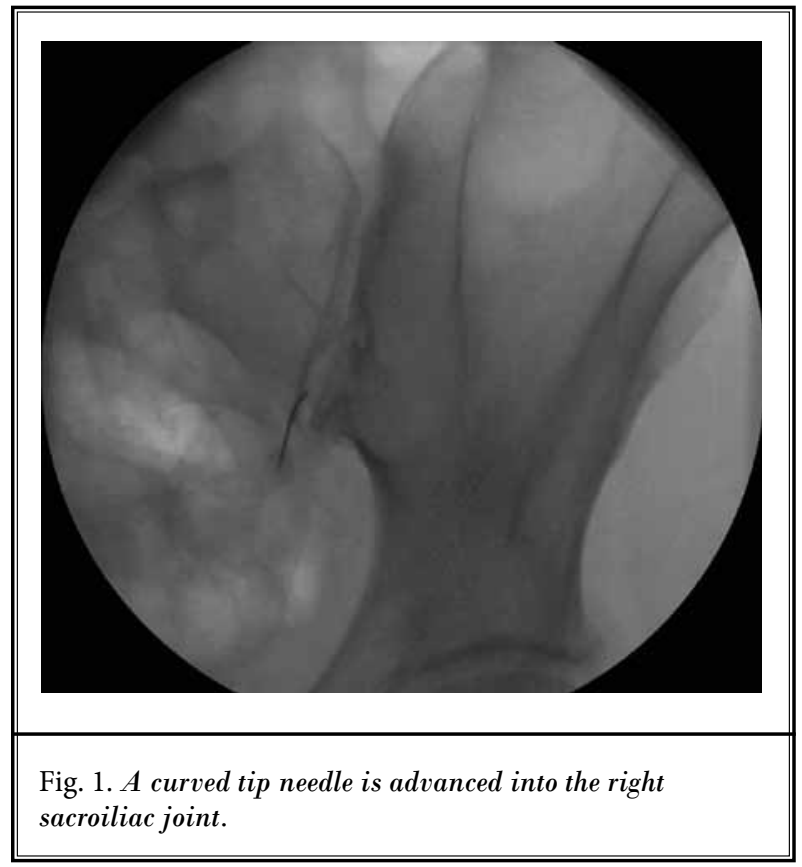

\section{Discussion}

The SIJ is a synovial joint, the upper two-thirds of which become more fibrotic in adulthood, and hence the need to enter the SIJ in its lower third. The SIJ is diffusely innervated by several spinal nerves and can produce symptoms mimicking discogenic pain (11).
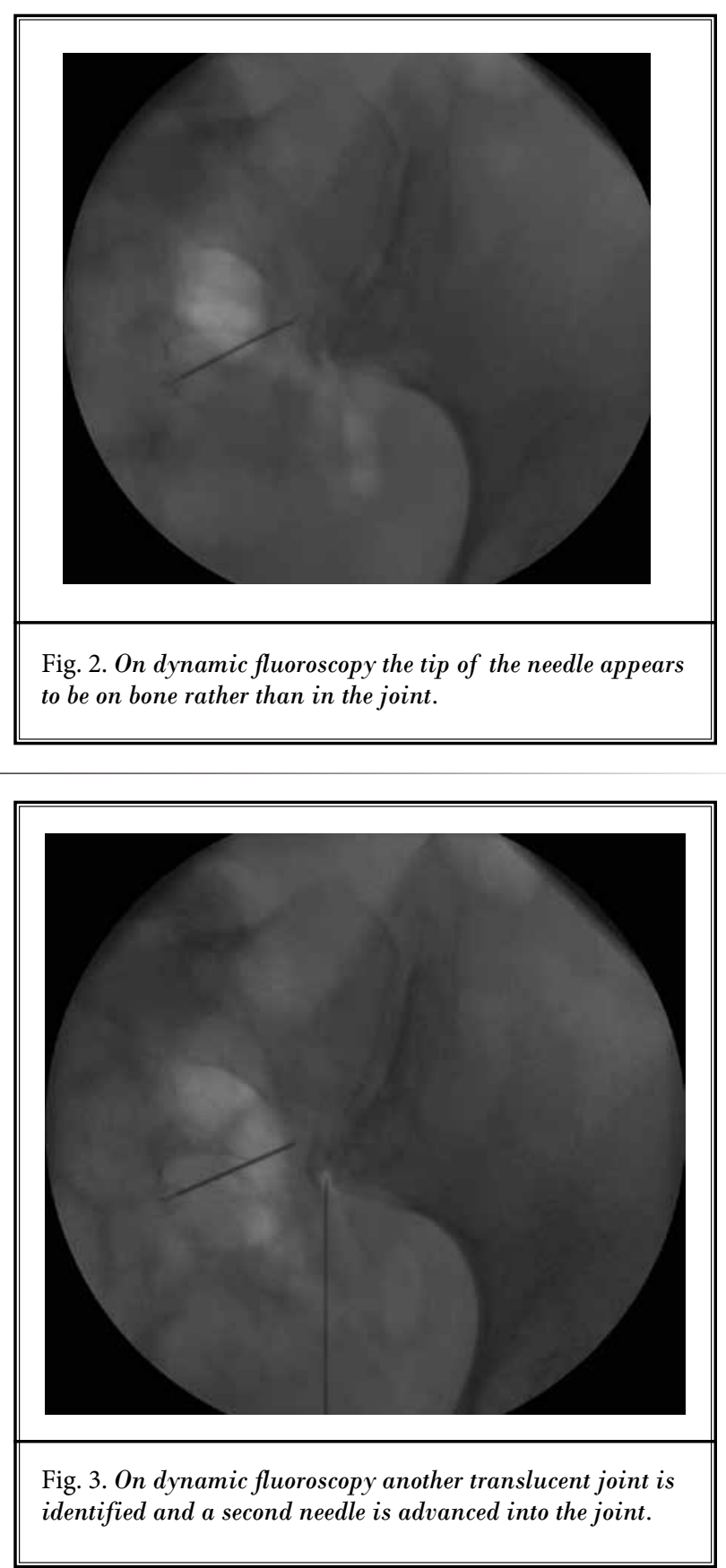


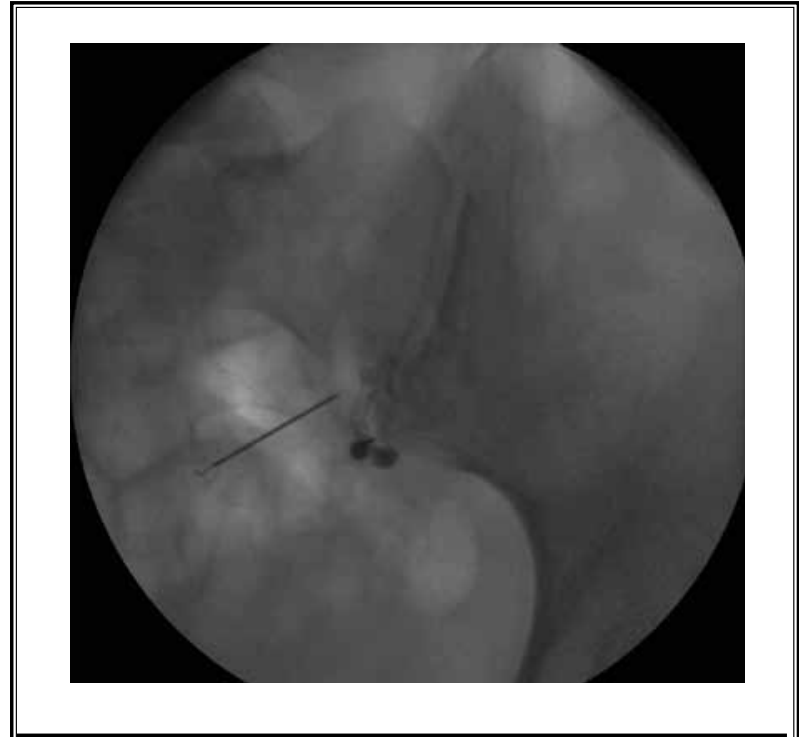

Fig. 4. Contrast is injected through the second needle. The lower one third of the sacroiliac joint is outlined

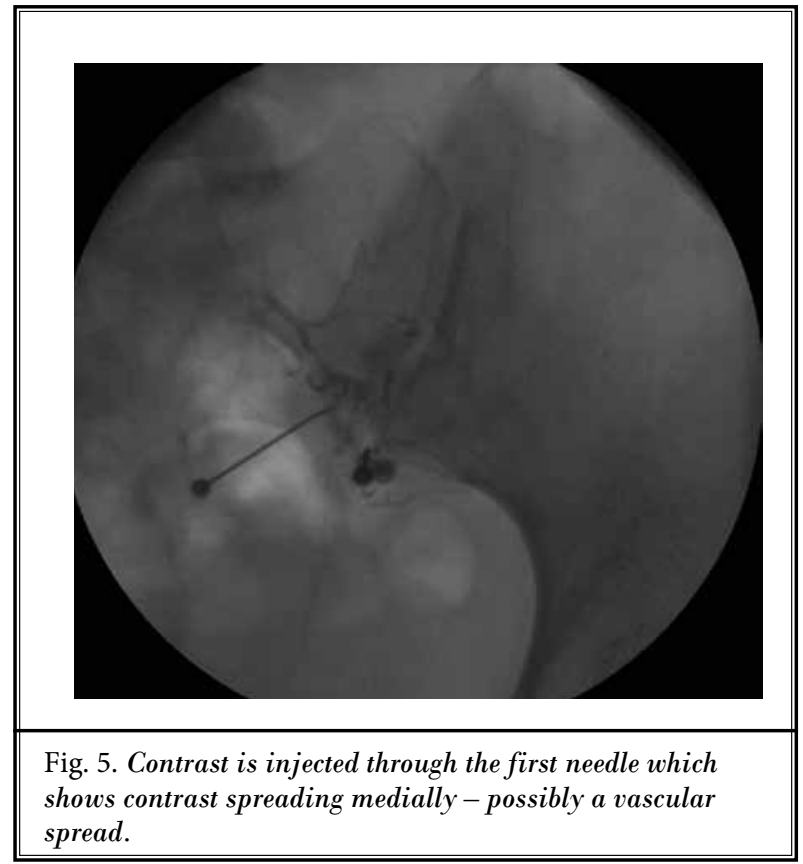

conventional single needle technique. To my knowledge 2 techniques have been described; one technique describes that the $\mathrm{C}$-arm be angled in such a way that the lines of the posterior and the anterior aspects of the SIJ are seen to overlap to obtain a radiolucent line along the joint line before inserting the needle into the lower third of the SIJ and injecting contrast dye to confirm that the needle tip is correctly placed (1). With the second technique the anterior and the posterior SIJ lines are separated. Generally in the anteroposterior view, the medial joint lines correspond to the posterior joint lines. By dynamic fluoroscopy the posterior joint lines are aligned to obtain a zone of maximum radiolucency and the inferior third of the joint is entered $(15,16)$.

I have used the above 2 techniques successfully. However, in some patients when I am not convinced that the needle tip is in the SIJ, I have used the double needle technique described above with good success. Although using the double needle technique increases the chances of appropriate injection into the SIJ, in rare instances both needles may not be within the joint. I have had one patient in whom the contrast dye spread was not satisfactory despite using the double needle technique. Is there a role for a third needle? That is a matter of judgment for each clinician.

In Figs. 3 and 4 the anterior and posterior sacroiliac joint lines are aligned only in the lower one 
centimeter of the joint where the SIJ has been entered. In clinical practice I find that at times it is not possible to align these joint lines to obtain a crisp, single translucent SIJ line. In these situations the most translucent area at the junction of the anterior and posterior joint lines will need to be entered. If after all these precautions one finds that the tip of the needle has moved on to the bone on dynamic fluoroscopy, then a double needle technique as described above can be helpful.

In my opinion, the double needle technique improves the chances of successful intraarticular injection in a selected group of patients. However, it can also increase the time needed to do the procedure, increase radiation exposure, and the chance of infection.

\section{References}

1. Sacroiliac Joint Injection. In: Raj PP, Lou L, Erdine S, Staats PS (eds). Radiographic Imaging for Regional Anaesthesia andPain Management. Churchill Livingstone (Elsevier Science), Philadelphia, 2003, pp $242-244$.

2. Solonon K. The sacroiliac joint in light of anatomical, roentgenological and clinical studies. Acta Orthop Scand Suppl 1957; 27:1-127.

3. Ikeda R. Innervation of the sacroiliac joint. Microscopic and histological studies. J Nippon Med School 1991; 58:587596.

4. Rupert MP, Lee M, Manchikanti L, Datta S, Cohen SP. Evaluation of sacroiliac joint interventions: A systematic appraisal of the literature. Pain Physician 2009; 12;399-418.

5. Manchikanti L, Boswell MV, Singh V, Derby R, Fellows B, Falco FJE, Datta $S$, Smith HS, Hirsch JA. Comprehensive Review of neurophysiologic basis and diagnosis interventions in managing chronic spinal pain. Pain Physician 2009; 12:E71-E120.

6. Manchikanti L, Datta S, Gupta S, Munglani R, Bryce DA, Ward SP, Benyamin RM, Sharma ML, Helm S, Fellows, B, Hirsch JA. A critical review of the Amer- ican Pain Society clinical practice guidelines for interventional techniques: Part 2. Therapeutic interventions. Pain Physician 2010; 13;E215-E264.

7. Manchikanti L, Boswell MV, Singh V, Benyamin RM, Fellows B, Abdi S, Buenaventura RM, Conn A, Datta S, Derby R, Falco FJE, Erhart S, Diwan S, Hayek SM, Helm S, Parr AT, Schultz DM, Smith HS, Wolfer LR, Hirsch JA. Comprehensive evidence-based guidelines for interventional techniques in the management of chronic spinal pain ASIPP - IPM guidelines. Pain Physician 2009;12;699-802.

8. Hansen $H$, Manchikanti L. Sacrioliac Joint Injections. In: Manchikanti L, Singh $\vee$ (eds). Interventional Techniques in Chronic Spinal Pain. ASIPP Publishing, Paducah, Ky, 2007.

9. Manchikanti L, Singh V, Pampati V, Smith HS, Hirsch JA. Analysis of growth of interventional techniques in managing chronic pain in Medicare population: A 10-year evaluation from 1997 to 2006. Pain Physician 2009; 12:9-34.

10. Manchikanti L, Datta S, Derby R, Wolfer LR, Benyamin RM, Hirsch JA. A critical review of the American Pain Society clinical practice guidelines for interventional techniques: Part 1. Diagnostic interventions. Pain Physician 2010; 13:E141-E174. 11. Simonian PT, Routt ML Jr, Harrington RM, Mayo KA, Tencer AF. Biomechanical simulation of the anteroposterior compression injury of the pelvis: An understanding of instability and fixation. Clin Orthop 1994; 309:245-256.

12. Grob K, Neuhuber W, Kissling R. Innervation of the sacroiliac joint of the human. Z Rheumatol 1995; 54:117-122.

13. Fortin JD, Kissling RO, O'Connor BL, Vilensky JA. Sacroiliac joint innervation and pain. Am J Orthop (Belle Meade NJ) 1999; 28:687-69o.

14. Yin W, Willard F, Carreiro J, Dreyfuss P. Sensory stimulation-guided sacroiliac jointradiofrequency neurotomy: Technique based on neuroanatomy of the dorsal sacralplexus. Spine (Phila Pa 1976) 2003; 28:2419-2425.

15. Sacroiliac Joint Blocks. In: Bogduk N, editor. Practice Guidelines- Spinal Diagnostic andTreatment Procedures. International Spinal Intervention Society, San Francisco, 2004, pp 66-86.

16. Dussault RG, Kaplan PA, Anderson MW. Fluoroscopy-guided sacroiliac joint injections. Radiology 2000; 214:273-277. 